\title{
Rising to the occasion: New persons for new times
}

\author{
Respondendo aos desafios contemporâneos: novas pessoas para novos \\ tempos
}

\author{
Maureen O'HARA'
}

\begin{abstract}
Global problems are accelerating to the point where they are challenging civilization. The author reflects on how early mentors in Biological and Psychological science modeled a new paradigm for their inquiry that included subject-subject participation, qualitative methods, a wider range of accepted evidence and the ability to indwell in a state of "not knowing" and letting coherence emerge. Such an approach not only leads to new knowledge but also develops capacities and competencies in the researcher that are more adequate for understanding complex and seemingly intractable crises of global the 21st century. The author identifies three levels of crisis occurring simultaneously: conceptual, cultural and existential which undermine coherence at personal and societal levels. When societies destabilize doubt and uncertainty rise producing the possible responses of defensiveness, anarchy and transformation. To optimize the possibility of transformation a new kind of psychology is needed that is better adapted to current conditions. Persons of Tomorrow, a term coined by humanistic psychologist Carl Rogers during the upheavals of the 1960s, have the consciousness and capacities to address these crises in creative and transformative ways. The non-profit International Futures Forum has developed theory, pedagogy and social practices to facilitate transformative innovation. Case examples of its and others' transformative projects are described and linked to the urgent need to develop and to practice as Persons of Tomorrow.
\end{abstract}

Keywords: Awareness; Cultural crisis; Evidence; Future; Subject.

\section{Resumo}

Os problemas globais estão aumentando a tal ponto que ameaçam a civilização humana. A autora reflete sobre como seus mentores das áreas de Biologia e Psicologia desenvolveram um novo paradigma em suas pesquisas que se caracteriza por contemplar uma relação sujeito-sujeito entre o pesquisador e o participante da pesquisa, métodos qualitativos, uma gama mais ampla de evidências comprovadas e a habilidade para colocar-se numa posição de "não saber' de forma a permitir que a coerência sobre algo possa surgir naturalmente. Tal abordagem, não apenas leva a novos conhecimentos, como também desenvolve capacidades e competências no pesquisador que são mais adequadas para compreender as complexas e aparentemente insolúveis crises do século 21. A autora identifica três níveis de crises ocorrendo de maneira simultânea - conceitual, cultural e existencial - e que tendem a solapar a coerência nos níveis pessoal e social. Quando as sociedades se desestabilizam dúvidas e incertezas aparecem produzindo reações de defesa, anarquia e transformação. Para otimizar a possibilidade de transformação, faz-se necessário um novo tipo de Psicologia, mais adaptado às condições atuais. Pessoas do Amanhã, um termo cunhado pelo psicólogo humanista Carl R. Rogers durante os conflitos da década de sessenta do século XX, possuem a consciência e as capacidades para enfrentar estas crises de modo criativo e transformador. A Futures-Forum, uma organização sem fins lucrativos, desenvolve teorias,

${ }^{1}$ National University, College of Letters and Sciences, Department of Psychology. 11255 North Torrey Pines Rd., 92037, La Jolla, San Diego, CA, United States. E-mail: <mohara@nu.edu>. 
estratégias pedagógicas e práticas sociais visando facilitar inovações transformadoras Exemplos deste e de outros projetos transformadores são descritos e também associados a urgente necessidade do desenvo/vimento de uma prática no estilo das Pessoas do Amanhã.

Palavras-chave: Conhecimento; Crise cultural; Evidência; Futuro; Sujeito..

\section{Blessed mentors}

Let me start on a personal note. I have been astonishingly blessed in my mentors and colleagues and I would not be speaking today if I that had not been the case. I began my academic life as a biological researcher in Britain in the 1960s. I was not a particularly stellar student as an undergraduate. But I was lucky. I was accepted to do doctoral research under the tutelage of a brilliant and eccentric microbotanist, Dr. Irene Manton, who has the distinction of discovering some fundamental aspects of cellular structure using the newly invented electron microscope (Preston, 1990). Back in those early days of electron microscopy nobody understood what they were seeing. All one could see on the screen was a field of features that didn't make any sense. Manton's key lesson was that inquiry at the edge of new knowledge is more like listening to music or art appreciation than it is engineering. A researcher going where no one had gone before has to enter into a subject-subject relationship with her subject matter allowing the meaning of an image to emerge out of a ground of indistinct marks. Manton taught her students to gaze at their material like lovers. To help us see she covered our lab walls with original works of some of the 20th century masters among them Klee, Kandinsky, Miro, Matisse, and Munch that she had collected in Paris as a young women in the 1920s - and she encouraged us to spend time soaking in the images. Under her guidance I learned to let go of preconceptions, trust my own sense making, and indwell in the mystery of the unknown.

When I moved to the United States I switched disciplines to study psychology. Here I was lucky again when American psychologist Dr. Carl Rogers agreed to be my doctoral adviser. Along with his work as a psychologist Rogers was also a gardener, mobile maker and nature photographer. Above all he was a participant in life and he allowed life in many of its manifestations to speak to him in its own language. On his many trips he was always willing to get outside his familiar contexts and immerse himself in local traditions. He might attend sessions with shamans, go to civil society gatherings, talk to spirits, and join in traditional dances and festivals. He too, had a wider view of what we should consider "evidence" in our inquiries using qualitative methods, field work, case studies and walks along the beach. He too could suspend preconceived ideas to let implicit order emerge and like every good scientist he subjected his observation to critical review by others.

Rogers and I worked together for two decades on a project exploring the application of Rogerian principles to large group and community dynamics. With a team of colleagues we designed temporary learning communities of up to 1000 participants and convened them in diverse societies around the world including North and South America, segregated South Africa, pre-Perestroika Soviet Union, Europe, China and Japan (Rogers, 1977; Bowen, Miller, Rogers, \& Wood, 1979; Rogers 1980; O'Hara \& Wood, 2004; Wood, 2013). Like Manton with her electron micrographs we didn't know what we were looking at at first. Our project was aimed at finding out if large group encounters might provide a context for developing higher order cognitive and emotional intelligence (Bowen et al., 1979). The existing research on social systems dynamics seemed to us to lack the human depth that we were experiencing in these encounters. Instead we wanted a more personal, holistic and embodied sense of the process. We used a participatory method that was a departure from the way most experimental behavioral scientists 
approached their inquiry but was consonant with the way clinical encounters were studied. The team included individuals trained in diverse modes of inquiry including Social Science, Biology, Political Science, Clinical Psychology, Plastic Arts and a Martial Arts Sensei. We were all convinced of the need for evidence but accepted a wider definition of what should count as evidence. We entered into the dynamic swirl of the community process as persons, not as at distant objective observers but as reflective participants. We learned through lived experience as Subjects collaborating with other Subjects in a joint endeavor.

I dwell on what I learned working with these early mentors for three reasons. First to acknowledge my indebtedness to them for teaching me to know the world as a participant and not only as an observer. Secondly to suggest that in unknown territory it is more fruitful to take the stance of a learner rather than as a controller. And thirdly because I want to make the case that nothing short of a new paradigm for knowledge and new ways actions will be needed to address the seemingly intractable challenges we face. Choices we make in the next decades as persons, in institutions, and as a species may determine the fate of life on earth.

\section{Converging crises: A "perfect storm"}

I want to argue strenuously that in a world that is undergoing radical shifts on multiple levels using the old approaches hoping to generate different outcomes is not only neurotic and futile but it is probably making things worse. If we fail to develop new ways of being, thinking and acting and instead continue on our current path outcomes could be truly catastrophic. In the face of the cascade of interconnected global problems occurring in every region of the earth the temptation is great to stick to what has worked in the past. But to paraphrase Einstein, the same kind of thinking that created the threats are unlikely to be able to get us out of them. Of course there are many forces that conspire to keep us using outdated conceptual paradigms and to employ solutions that worked well in an industrial age. But evidence from the crises in large institutions such as governance, health care, public education, policing and energy suggest that yesterday's ideas are rapidly losing effectiveness in today's circumstances. Though there are many dimensions of the crises, as a psychologist my focus is on the implications for psychological health and effectiveness in times that are more powerful than our minds.

As evidence from multiple sources mounts it becomes ever more obvious that our entire planet and its inhabitants are in very deep trouble. Deeper than most of our leaders will admit. As the creative cumulative product of over two hundred thousand years of human aspiration, ingenuity and industry we now have a world that has outstripped our capacity to make sense of. The scale of connectivity and interdependence has resulted in a "perfect storm" of threats and we are adrift in a world that we don't understand and can no longer control (Leicester \& O'Hara, 2009). In any one week sometimes in a single day - events occur that would have been literally unthinkable a generation ago. They would have been so far outside the conceptual frames people use to make sense of the world as to make no sense at all, and likely to either be ignored or to generate intense anxiety. Sectarian conflicts, rampant corruption, religious, ideological and scientific fundamentalism, terrorism, a widening gulf between the superrich and the destitute with a shrinking middle class squeezed between them, and instantaneous and polarized media coverage of atrocities and misery anywhere they occur, to name a few, all have significant destabilizing effects from which no one is immune. The human toll in mental distress is rising exponentially even in affluent societies, and disastrously in poorer regions (World Health Organization, 2017).

We know from archeological and historical studies of fallen empires that systemic stress of this kind is enough to threaten the survival of entire civilizations (Diamond, 2005). But what makes our 
current situation even more perilous is the fact that these disruptions are occurring within a far more terrifying context of potential ecosystem collapse. This time we may be looking at more than the end of empires but the possible extinction of the human species.

In our work in the International Futures Forum (IFF), a Scottish and United States community of scholars and practitioners, we identity three kinds of crises that are challenging people and organizations everywhere. There are conceptual crises, where the psychological anchors of identity, wellbeing, shared knowledge, relational rules and customary forms of action are no longer adequate to the current conditions. There are also cultural crises occurring in many cultures where long standing patterns of life, values and mores, governance, institutions and patterns of commerce that together have sustained social arrangements and enterprise have reached a level of complexity beyond anyone's capacity to understand let alone manage. And so communities have become ungovernable lurching from crisis to crisis that threaten to tear them apart. Beyond this and more long term an existential crisis looms in which multiple factors are coalescing to threaten extinction of life on this planet.

If we are to head off the worst of these outcomes from these unprecedented crises we will need to resist the neurotic denial of their seriousness and reject the siren call for technical fixes based in the old kind of thinking. Instead, for signs of hope we need to look to the human imagination and seek out creative innovations within our communities and organizations that might help us cope with the crises and lift us to a new sustainable reality.

\section{Consciousness and culture}

Every culture or historical era produces its own particular psychology and characteristic social arrangements and idealized mental profiles. Contemporary cultural psychologists have identified a range of culture-originated variations in consciousness. These include differences in identity, perception, motivation, meaning making, brain development, emotional response, how we learn, epistemology, technical knowledge, ethics, conceptual strategies like logic and analytic frames. As long as conditions remain constant the relationship between the life-worlds people inhabit and their internal psychological landscape is reciprocal and coherent. What people expect is borne out by their experience in the world, and the world makes sense. The model of acceptable or ideal ways of being a well-integrated "person" also varies from culture to culture sustained by ideas and practices deeply woven into daily life, the public sphere of laws, commercial patterns and entertainment, and the artistic and ritual life of the society. The all-powerful Julius Caesar consulted augers and made his political decisions accordingly. Ancient Egyptian farmers looked to the night sky and the water table to time the planting of crops, and executives in 21st century multinational corporations rely on stock prices, chains of command, highly paid experts and big data. We make decisions that are in accord with the narratives we live by. Decisions sometimes prove erroneous of course but in stable societies when that happens the errors are explained away - the auger may be a spy, the Chief Financial Officer incompetent - but few question the worldview underpinning the decisionmaking process. But in turbulent or destabilized societies responses take on more systemic import. Revered customs and taboos are no longer followed, customary procedures challenged, and rituals that were once compelling lose meaning. Factions adhere to alternative truths and social consensus fragments. Fundamental uncertainty rises and with it existential anxiety (Leicester \& O'Hara, 2009). When things in the external world contradict deeply held values, cognitive frameworks, or sense of reality, this sets up cognitive (and emotional) dissonance and results in a conceptual emergency. Zygmunt Bauman calls such as state "liquid times" (Bauman, 2010; O'Hara, 2010).

There are three different responses to such conceptual emergencies. Whichever of them plays out is mostly a function of how extreme is the 
emergency and how resilient or vulnerable a person or group is. The most common response is defensive. It may take the form of denial that anything has changed, finding scapegoats to blame, suppressing deviance and restoring an old sense of order through rigid rule making - by force if necessary. Norgaard provides an example of collective denial in a Norwegian town which functions to retain the patterns of life of a "snow town", even though there has been no appreciable snowfall in years (Norgaard, 2011). Though normal and as a short-term response probably adaptive, defensiveness requires effort and reduces creativity. Furthermore, if it is to be sustained over time, it consumes more and more energy and sometime force to hold the old ways of life together. The wider the gap between tradition and new conditions the more resources must be consumed to resist change thus heightening the anxiety and reducing effectiveness. Another, more dangerous response is to allow order to collapse, abandon rules, let consensus disintegrate and anarchy descend. In such a breakdown aberrant conduct becomes normalized as rules that were developed to coordinate collective behavior are violated with impunity. Nothing is dependable, decisions are arbitrary and a common view of truth no longer organizes action. Both denial and breakdown reduce resilience and narrow options for creative responses to a changing world. A third possibility is growth and this points the way for transformative reorganization at the level of individuals and of communities. When there is enough resilience and support in the system a certain amount of disorder can be tolerated. If people can remain in the state of uncertainty long enough self-organization into higher levels may be possible. Cultural turbulence may sometimes break up past rigidities opening up new spaces for experimentation so creative initiatives flourish and adaptive capacities emerge.

\section{Existential risk}

There is a rising consensus among forecasters 458 in en route to disaster. If we do not change course rapidly and radically, in the long run we risk annihilation or at least irreversible disruptions in our existing ways of life. These challenges are now thought to pose a "global existential risk" that "threatens premature extinction of Earth-originating intelligent life" (Bostrom, 2013, p.15). There may still be hope that we might be able to avoid the more catastrophic outcomes but the window of possibility is rapidly shrinking (Rees, 2013; Ceballos et al., 2015). The June 1, 2017 decision by United States President Donald Trump to withdraw from the Paris Climate accord is not a hopeful sign.

There are some sources of hope, of course, and many point to exponential growth in innovative technologies, especially in alternative energies, biotech, nanotechnology, robots, information and communication technology that will ensure that humanity endures and thrives. But in my view as a psychologist I believe the challenge is more psychological than technical. Whether we put technologies to use to save the planet and to protect people from the worst of what is to come will depend on whether we can find and use ways to reach higher levels of psychological capacity and become smarter and more creative.

\section{Unravelling coherence}

Much of what is known about past civilizational collapses like the Roman, Egyptian and Mayan, focuses on issues such as catastrophic upheavals of war and cataclysmic environmental events (Diamond, 2005; Cline, 2014). Less often discussed, however, is how such upheavals influence mental equilibrium and the collective sense of coherence.

There is strong evidence that a solid sense of coherence is a need as basic as food and shelter and when coherence is weakened it makes it much harder for us to cope with threats or to make the most of innovative opportunities (Carson, 1962; Maslow, 1970; D. H. Meadows, D. L. Meadows, 
Randers, \& Behrens III, 1972; Antonovsky, 1979; Anderson, 1987; Kegan, 1994; Michael, 2010; O'Hara \& Leicester, 2012; Stromberg, 2013; Cline, 2014; Hämäläinen, 2014; Dror, 2015; Anderson, 2016). In the decades I spent working as a Rogerian psychotherapist with individuals, families and groups, I listened to a wide diversity of stories of people who were in the process of trying to make sense of their lives. I began to see that although the stories were deeply personal there was also the murmur of a deeper story. People were trying to make sense of a world where inherited anchors of certainty, identity and moral clarity were unraveling and they were trying to make their way in the world without any guide, map or compass (O'Hara, 2006; 2007; 2010). This cultural story is both intensely personal and universal. The value of a good therapist is not that they point out the way forward, but that they create a relational context in which clients can work through their bewilderment and begin understand their struggles within a larger context. When this happens, old limiting constructs dissolve and more create paths forward path forward take their place.

\section{New personhood}

It is becoming highly likely that as modern culture unravels the psychological profile privileged by advanced technological western democracies with its emphasis on individualism, abstraction, analytic rationality, detachment and objectivity and is no longer adaptive. To solve the intractable problems of late modernity we will need people with different mental profiles and capacities of mind and customs better adapted to liquid times. Rogers called such people "Persons of Tomorrow". These new persons will need to develop an expanded range of capacities necessary that will enable them to thrive in the industrial culture while it is disintegrating and to have the flexibility to go beyond the constraints of modernity to adapt to the new world that is emerging in the 21 st century.
The good news is that even though the dominant psychology was developed to thrive in advanced technological societies such persons ready to make their way in rapidly changing and confusing contexts, are with us today. No culture is homogeneous and counter cultural pockets always exist - often among the young who are not yet socialized into the patterns of the mainstream. In "A Way of Being", Rogers describes the consciousness of counter-culturals who were navigating the turbulent 1960s and 1970s. He reports that these new persons are open to experience, desire authenticity, enjoy diversity, live in the process, value intimacy, distrust bureaucracy, are caring and empathic, less materialistic and seek spiritual fulfillment (Rogers, 1980). He observes, with amazing prescience, "the striking thing is that these persons... will be at home in a world [...] with no solid base, a world of process and change, in which the mind, in its larger sense, is both aware of, and creates, the new reality" (Rogers, 1980, p.352). In Rogers' view persons of tomorrow have resilience, creativity and courage to look at the emerging future and make themselves at home in it, and they have the competencies to make a difference. "They will be able to make the paradigm shift" (Rogers, 1980, p.352).

So where are the sources of hope for the current generation? Even in these darkening times are their possibilities for transformative innovation that could head off the worst and perhaps point the way to a more human and sustainable future? I believe there are.

\section{Supporting transformative practice}

The questions of whether humanity could make a paradigm shift and if so, how it might be facilitated at scale was at the heart of a project launched some thirty years after Rogers first considered the question of a psychology for the future. In 2000 along with thirty experts from multiple disciplines I joined the IFF, in Saint Andrews, 
Scotland. The project was to develop new theory and practice that could support transformative innovation and restore effectiveness in action in today's powerful times (Leicester \& O'Hara, 2009).

The original plan was to meet for two years, ... to explore the nature of the most significant future challenges facing society and the systemic connections between them; to examine ways in which we might successfully adapt and respond to these challenges, including by learning from existing promising practice; and to stimulate actions consonant with that inquiry by individuals, communities and at a systemic level, in Scotland and elsewhere (Leicester, 2016).

Now in its 17th year IFF's practice is to find ways to support individuals and institutions experiencing both an aspiration for something better and frustration that little they do seems to get them nearer their goal.

Group members were selected whose own work expressed the idea that predominant ways of looking at the world that emerged in the Enlightenment and the modes of thought and action perfected during the industrial revolution were inadequate to today's challenges and far from providing solutions had become part of the problem. With duly acknowledged hubris we saw the project as a multi-disciplinary inquiry into the possible contours of a new Enlightenment theory and practice - that could offer more useful frameworks, increased sources of knowledge and expanded consciousness with which to address the huge problems going on around us and make a transformative difference. We convened at the Old Course Hotel in Saint Andrews - ironically a bastion of Western male privilege - to try to come to grips with a world too complex to either understand or control.

Our encounter with the limits of our own ingrained habits and assumptions began early in the first meeting. We quickly realized that if you put thirty experts together and ask them to questions you don't get new thinking you get dueling egos and highly abstract answers. After that meeting we concluded that if we wanted a deeper understanding of the world we are living in we first needed to engage it. So we took a leaf out of Rogers' and Manton's books and opted for an immersive, participatory process - one where we sought to act ourselves into new modes of thinking in contrast to trying to think our way into new ways of acting.

In the years since then there has developed a substantial collection of IFF theory that is now guiding practice in diverse contexts. Much of this is published and available through the IFF website (www.internationalfuturesforum.com).

International Futures Forum practice is based on a variety of change and growth practices from psychotherapy, anthropology, folk lore, education, organizational practice, spiritual practice and the arts. From the start we were interested in finding existing examples of transformative innovations where transformative solutions to the conceptual and cultural emergencies were evident, changing not just how a game - such as health care or education is played but changing the game itself.

To better understand what personal and organizational capacities lead to such transformative innovation we asked people facing intractable challenges to point to projects, organizations and leaders who seemed to be thriving and getting things done in the complexities of 21st century contexts. As described in our book, "Dancing at the Edge" (O'Hara \& Leicester, 2012) we shadowed people identified by others as transformative leaders and partnered with organizations and communities struggling to make a transformative difference despite all that gets in the way of making a difference. We realized, as Rogers and Manton had decades before, that if we wanted to grasp the intricacies of complex systems and assist leaders to make a truly transformative difference, we need to leave our expertise (and egos and agendas) at the door and show up as whole persons ready to sit in the messiness for a while and learn our way forward. 


\section{Collective learning to increase social capacity}

The International Futures Forum learning process is a social learning process that is both collaborative and experiential. We rely on methods such as facilitated dialogue, café conversation, shadowing, simulations, civic conversations, dilemma analysis and scenarios. Several projects involved learning journeys (an approach originally developed by the San Francisco-based Global Business Network described by Boyer (2011) as "a process and practice for exploration and discovery through having intense immersive experiences developed to surface, test and shift key assumptions" (p.1). In our experience, a crucial element in any transformative processes is that it requires the suspension of prior frames to immerse in new realities. This takes psychological courage and support. When IFF partners with a an individual or group the IFF team acts as a set of tuning forks within the orchestra - the economist listens for economics threads, the social scientist for the social forces, the poet creates a poem, the psychologist listens for emotion, myth, resilience and compassion. In a postencounter debrief each member of the team shares what they felt, heard, saw and experienced and the team works with these reflections until a collective picture emerges that allows for both the IFF team and the client team to re-perceive their situation. This picture is then tested against the clients' sense of their challenge. IFF's aim is to trust the embodied knowledge of the people who are the "owners" of the challenge and to trust the human process as a way to get as deep and comprehensive as possible a sense of the challenges and strengths from the client's point of view. From this process which is both analytic and synthetic it is usually possible to identify signs, however faint, of the creative impulse already present in the group. In making the implicit explicit hope is restored and whatever barriers might be impeding innovative possibilities reduced. This is epistemologically equivalent to the process used by my mentors Manton and Rogers, both in their own sphere of inquiry, to identify patterns, get below the surface and identify emergent possibilities in the present and offers promise as a mode of inquiry for liquid times.

\section{Transformation in action}

In a project in 2002 in Falkirk Scotland, the city manager asked for help with a regional renewal project that had been prompted by the closure of the refinery that was a major employer in the region. The city council already had a strategic plan but the manager and some of her staff knew they were capable of something bolder and more transformative. The IFF group went on a learning journey to several communities and organizations and listened to everyone who had some kind of commitment to solving the problems and inventing the future. We listened to their stories of hopes, disappointments, successes and failures. We listened for theoretical frames, metaphors, themes, emotions, imaginings and visions. We walked around in the spaces where citizens lived and worked and imagined with them how it might be in the future. We held conversations with social service providers and their clients. We joined groups of townspeople, chief executive officers, local officials, employees and children trying to open ourselves to their situation and their humanity. We met with people who were technically highly competent but who wanted to go beyond the usual strategic planning process to invent a future for their children that was worthy of their highest aspirations. So we allowed ourselves to become involved at many levels. With the citizens of Falkirk we faced the messiness of a future that through no fault of their own was going to be very different from the past. We felt their sense of overwhelm, grieved with them in their loss of past success and with our ears to the ground we listened for signs of the creative impulse which even in troubled contexts is never far below the surface. And gradually a new future oriented consciousness emerged and a new bolder - empowered - psychology was evident. Importantly this new vision did not come from the IFF members but sprung up among them as they engaged with the reality of the situation. The management team was reinvigorated, eager and were figuratively holding each other's hands, ready to take a risk. Once the collective imagination was fired up the creative vision they conjured up of a 
possible Falkirk became impossible to ignore. Ten years later Falkirk and its region is thriving socially, educationally. The project is described in detail by O'Hara (2016).

Another learning journey took us to India, invited by an Indian IFF member to "come see signs of hope where one would be least expected to find them". We saw many inspiring examples of transformative creative responses to seemingly hopeless situations. In a huge Delhi slum, for instance, non-reading local women showed us how with the help of a couple of social workers who were literate they were able to use the Freedom of Information Act to find out who was stealing money meant for clean water and baby food. The Fife SHINE project in Scotland supports innovation in National Health Service - Scotland to help elders live longer and healthier lives at home. SHINE started with five frustrated health care workers who believed health could be improved and costs lowered if elders were considered resources not costs. SHINE now involves over five hundred health care workers across Scotland. IFF also builds resources that people can use without paying professional fees they can't afford. The Higher Education Transformation Kit is used as a do-it-yourself guide to convene generative conversation about transforming higher education using the combined wisdom of people trying to make a difference to create spaces for innovation. Kitbag is a collection of self-care resources based on principles of resilience, self-direction, relational competence, wellness and growth. Early on in the IFF practice a pack of Prompt Cards was developed from the pearls of wisdom that showed up on workshop flip charts. They are now used by individuals and groups to provoke new ways of thinking at any moment. Other projects have included a workshop kit to nurture Third Horizon Thinking in Health Care. Futurist Anthony Hodgson developed the World Game simulation that helps groups explore a holistic, data informed conversation about planetary sustainability. The Goven Health and Resilience initiative empowers citizens to create healthier ways of life in a deprived area of Glasgow. The "Understanding Glasgow" website (www.understandingglasgow.com/) where citizens can find the information they need about their own community is now being replicated by several other European cities. A recent initiative is the National Infrastructure for Transformative Innovation project - described in Leicester's latest book, "Transformative Innovation" (2016) whose purpose is to provide peer support for transformative innovators. Starting as one breakfast meeting in London there is now a network of breakfast meetings in several United Kingston cities and one in the United States. IFF thinks of its projects as seeds - a kind of social acupuncture - which can stimulate others to try something themselves. Descriptions of these and other projects can be found in publications listed on the IFF website (http://www.internationalfuturesforum.com/).

But International Futures Forum projects are just a small part of a far larger movement of transformative innovation going on world-wide. It turns out there are "Persons of Tomorrow" everywhere one looks who are engaged in large and mostly small creative and effective initiatives to address the multiple challenges humanity faces in the 21st century. Festivals, conferences, arts events and design projects are springing up around the world as talented young people decide to step outside limiting frames. They have given up on mainstream institutions that seem less and less able to deliver what they were originally built for. Increasingly citizens who are awake to the crises bearing down and are motivated to make a difference, are deciding to take the work of creating a new civilization into their own hands. They are not waiting for established institutions to solve intractable problems but getting to work with a small group of like-minded colleagues to put their own skills to work solving problems directly. Recognition of the gap between the demand of the 21 st century and adequate preparation to deal with them is gradually filtering upwards into policy arenas. In Finland, for instance, the need for a transformed educational process for the new conditions of the 21 st century has prompted a shift in education in the direction of "phenomenonbased learning" which students have a role in 
designing and is aimed at cross-disciplinary action learning. The aim to ensure that kids develop the necessary cognitive and emotional capacities to thrive in the emerging circumstances of the $21 \mathrm{st}$ century (Sahlberg, 2015).

\section{Expanding what we think of as resources}

Participants in IFF have come to believe that the consciousness of a "Person of Tomorrow" is developed not in the classroom - at least not in the mainstream classrooms of modernity - but in action projects in the real world. Just as the modern mind emerged through participation in a secular world of science, machines, alienation from nature, power hierarchies of class, gender, and race, people become "Persons of Tomorrow" by engaging in the realities of 21st century culture. We have also come to believe that new competencies are not developed in isolation but through working with partners in those messy situations that require us to change, grow and learn. When people take on a seemingly intractable mess the actions needed to make a difference and feedback in response become the contexts for learning new ways of being.

The skills and mental frames of the modern world were built by the current technologically sophisticated, democratic cultures. These are still needed. But as today's civilizations run up against their limits, as catastrophe looms, additional sources of wisdom must now be found with which to navigate future unknown paths. Fortunately we don't have far to look. There exists a reservoir of human capacities which were ignored or driven to the margins by the hegemonic power of the Enlightenment and modern science. These sources, still rejected as "science" and deemed unreliable by gatekeepers of the status quo are nevertheless still with us in vernacular psychologies and indigenous psychologies of people less colonized by Western consciousness (Shweder, 1991; Sundararajan, 2005). They can also be found in post-positivist philosophy, qualitative research methods, historical records, consciousness practices, folk tales, the arts and humanities and can be brought back into service as pathways to truth and to provide expanded views of the possible.

The good news is that there are literally millions of people world-wide who are engaged in transformative actions, much of it aimed at the kind of huge problems I started out with and have the knowhow to reclaim these past capacities and put them to work. Many have the ability to marry advanced scientific methods and computer assisted analytics with older holistic skills such as dialogue, intuition, story, visual language, pattern recognition, folk experience, music and somatic wisdom. In his book "Blessed Unrest", cataloging what he calls with characteristic California flair the "largest movement in history", Paul Hawken lists over a million different non-profit and social enterprise groups world-wide that are working to bring about positive change. Of these around thirty five thousand address psychological, spiritual and community well-being. I conducted a word frequency search on descriptors used to describe these social transformation initiatives and found an almost universal commitment to the same basic principles. Awareness, participation, listening, empathy, empowerment, authenticity, transparency, sustainability, communication, appreciation, dialogue, flexibility, tradition, ritual, mutual respect, collective deliberation, diversity, trust, self-governance, group wisdom, transformative conversation, collective intelligence, distributed intelligence, respectful relationships, non-violence and social justice are among the most common terms (O'Hara, 2013).

More significantly for the planetary prospect, in the missions of these non-governmental organizations there can be seen an outline of a new world view, one that goes beyond the technological mind, expands the ideal of what it means to be human, focuses on health, dignity and wellbeing, includes stewardship of the environment and what we must do to care for each other and for our home planet if we are to ensure a livable future. This suggests to me that the characteristics, competencies, values and practices 
Rogers identified in the turbulent 1960s as those of "Persons of Tomorrow" have now gone viral and become an open-source resource for transformative community development and social change across the world.

One cautionary note however, those who want to move towards a culture of tomorrow shouldn't be naïve. Disruptions to the status quo are not always or even usually welcome. When threatened the empire will strike back and try to resist paradigmatic change. This need not be a battle of new against old. The existing institutions and ways of life may be coming to the end of their shelf life but for now they are still the way things get done and people who work in these institutions are dedicated professionals doing he best they can in their settings. A great deal of human resources are dedicated to keeping them going. Persons of Tomorrow therefore, must develop the capacity to function in more than one world at a time, respecting the values of the old paradigms and at the same time expose their limits and offer alternatives.

\section{Rising to the occasion}

If we are to surmount the conceptual, cultural and existential crises that now threaten humanity and the rest of nature we need to mobilize our most precious resource - ourselves. We will need to become "hospice workers" for the dying culture (treating the wounded and those left behind with empathy, care and love) and "midwives" for a new world being born supporting people though the inevitable anxiety creating action. We will need facilitators who can create settings to nurture awakened citizen-leaders for the next stage of the human journey. We need designers of new organizational forms and we will need to sponsor initiatives in the service of a sustainable and humane global society. And above all, I suggest, it is urgent that as an alternative to the current narratives of despair, fear and division we promote narratives of with all the species on the planet. These narrative already exist in the hearts and minds of those who are making a difference.

We are in this together. At whatever level we have leverage we must avoid innovations that simply prop up existing dysfunctional paradigms, and offer a true alternative - a new world view, with ways of knowing, seeing, valuing, interacting, building communities, raising children, cherishing people throughout their lives and making judgments that reflects this new story. The future culture that our descendants will inhabit and be formed by will be built by choices we make now and by taking transformative action that takes us beyond the received frames of the last two hundred years.

So let me close with some practical ideas for how you might start becoming a cultural leaders. First start by going to the IFF website to find resources you can use and to find out that you are not alone. Then follow these simple steps - or explore your own.

- Identify a problem you would like to tackle and to which you think you have some contribution to make;

- Partner with those who need services and co-create your approach. Start where you are, start now. Take one small step in a humanizing direction and see what happens;

- Be humble. We don't know much;

- Don't make things worse. Always ask for feedback and follow up;

- Work with others. Find companions - two or three is enough - who will stick with it and be willing to learn as you go. Most successful initiatives are group activities;

- Join a group. IFF will support you if you ask (www.internationalfuturesforum.com). Or join some other group. There are many;

- Do research. Learn a simple holistic assessment method. Publish your story. This is the way a single event becomes shared actionable knowledge. 
If enough of us use our creativity in the service of transformation to a sustainable and humane future we just may find a way through the big "mess" we find ourselves in. And when it seems like it's too much - and it will - remember the words of writer Arundhati Roy, in her speech in Porto Alegre, Rio Grande do Sul, Brazil, not far from here, "Another world is not only possible, she is on her way. On a quiet day, I can hear her breathing" (Roy, 2003).

\section{References}

Anderson, W. T. (1987). To govern evolution: Further adventures of the political animal. New York: Houghton Mifflin Harcourt.

Anderson, W. T. (2016). We the planet: Evolutionary governance and biophilia in the anthropocene. Carlsbad, CA: The Meridian International Institute.

Antonovsky, A. (1979). Health, stress and coping: New perspectives on mental and physical well-being. San Francisco, CA: Jossey-Bass.

Bostrom, N. (2013). Existential risk prevention as global priority. Global Policy, 4(1), 15-31

Bowen, M., Miller, M., Rogers, C. R., \& Wood, J. K. (1979). Learnings in large groups: Their implications for the future. Education, 100(2), 108-116.

Boyer, N. (2011). Learning journey overview. San Francisco, CA: Adaptive Edge. Retrieved June 15, 2017, from http://www.adaptive-edge.com/wp-content/ uploads/2011/11/LearningJourneyOverview.pdf

Carson, R. (1962). Silent spring. New York: Houghton Mifflin.

Ceballos, G., Ehrlich, P. R., Barnosky, A. D., García, A., Pringle, R. M., \& Palmer, T. M. (2015). Accelerated modern human-induced species losses: Entering the sixth mass extinction. Science Advances, 1(5), e1400253.

Cline, E. H. (2014). 1177 B.C.: The year civilization collapsed. Princeton, NJ: Princeton University Press.

Diamond, J. (2005). Collapse: How societies choose to fail or succeed. New York: Viking.

Dror, Y. (2015). Priming political leaders for fateful choices. Eruditio, 1(6), 40-49.

Hämäläinen, T. J. (2014). In search of coherence: Sketching a theory of sustainable well-being. In T. J. Hämäläinen \& J. Michaelson (Eds.), Well-being and beyond: Broadening the public and policy discourse (pp.17-67). Camberley Surrey: Edward Elgar Publishing.
Kegan, R. (1994). In over our heads: The mental demands of modern life. Cambridge: Harvard University Press.

Leicester, G. (2016). Transformative innovation: A guide to practice and policy. Axminster: Triarchy.

Leicester, G. \& O'Hara, M. (2009). Ten things to do in a conceptual emergency. Axminster: Triarchy.

Maslow, A. H. (1970). Motivation and personality. New York: Harper \& Row.

Meadows, D. H., Meadows, D. L, Randers, J., \& Behrens III, W. W. (1972). The limits to growth. New York: Universe Books.

Michael, D. N. (2010). In search of the missing elephant: Selected essays by Donald N. Michael. Axminster: Triarchy.

Norgaard, K. M. (2011). Living in denial: Change emotions and everyday life. Cambridge, MA: MIT Press.

O'Hara, M. (2006). In search of the next enlightenment: The challenge for education in uncertain times. Journal of Transformational Education, 4(2), 105-117.

O'Hara, M. (2007). Strangers in a strange land: Knowing, learning and education for a global knowledge society. Futures, 39(8), 930-941.

O'Hara, M. (2010). Another inconvenient truth and the developmental role for psychology in a threatened world. The Humanistic Psychologist, 38(2), 101-119.

O'Hara, M. (2013). Person-centered approaches as cultural leadership. In M., Cooper, M., O'Hara, P. Schmid \& A. Bohart (Eds.), Handbook of person-centered psychotherapy and counselling (pp.483-495). London: Palgrave-Macmillan.

O'Hara, M. (2016). Make it personal: International Futures Forum's Approach to community transformation. In R., Motschnig \& D. Ryback (Eds.), Transforming communication in leadership and teamwork: Personcentered innovations (pp.99-106). New York: Springer.

O'Hara, M. \& Leicester, G. (2012). Dancing at the edge: Competence, culture and organization in the 21st century. Axminister: Triarchy.

O'Hara, M. \& Wood, J. K. (2004). Transforming communities: Person-centered encounters and the creation of integral conscious groups. In B. Banathy \& P. Jenlink (Eds.), Dialogue as a means of collective communication (pp.95-126). New York: Kluwer Academic.

O'Hara, M. \& Leicester, G. (2012). Dancing at the edge: Competence, culture and organization in the 21st century. Axminster: Triarchy Press.

Preston, R. D. (1990). Irene Manton. 17 April 1904-13 May 1988. Biographical Memoirs of Fellows of the Royal Society, 35, 248-261. 
Rees, M. (2013). Denial of catastrophic risk. Science, 339(6124), 1123.

Rogers, C. R. (1977). Carl Rogers on personal power: Inner strength and its revolutionary impact. New York: Dell.

Rogers, C. R. (1980). A way of being. Boston, MA: Houghton Mifflin.

Roy, A. (2003, 27 January). Confronting empire: Talk given at World Social Forum. Porto Alegre.

Sahlberg, P. (2015, 25 March). Finland's school reforms won't scrap subjects altogether. The Conversation. Retrieved June 15, 2017, from http://theconversation. com/finlands-school-reforms-wont-scrap-subjectsaltogether-39328

Shweder, R. A. (1991). Thinking through cultures: Expeditions in cultural psychology. Cambridge, MA: Harvard.
Stromberg, J. (2013, January). What is the Anthropocene and are we in it? Smithsonian Magazine. Retrieved June 15, 2017., from http://www.smithsonianmag. com/science-nature/what-is-the-anthropocene-andare-we-in-it-164801414/

Sundararajan, L. (2005). Happiness donut: A Confucian critique of Positive Psychology. Journal of Theoretical and Philosophical Psychology, 25(1), 35-60.

World Health Organization (2017, April). Mental disorders [Fact sheet]. Geneva: WHO. Retrieved, from http:// www.who.int/mediacentre/factsheets/fs396/en/

Wood, J. K. (2013). Summer of persons. São Paulo: Vis Lettera.

Received: June 27, 2017

Approved: July 7, 2017 